\title{
Etnografía de un conflicto habitacional. Desplazamientos teóricos y metodológicos desde una perspectiva pragmática
}

\author{
Ethnography of a housing conflict. Theoretical and methodological \\ displacements from a pragmatic perspective
}

\author{
Soledad Balerdi \\ soledadbalerdi@gmail.com \\ Instituto de Investigaciones en Humanidades y \\ Ciencias Sociales, Universidad Nacional de La Plata, \\ CONICET, Argentina
}

Cita sugerida: Balerdi, S. (2020). Etnografía de un conflicto habitacional. Desplazamientos teóricos y metodológicos desde una perspectiva pragmática. Revista Latinoamericana de Metodología de las Ciencias Sociales, 10(2), e080. https://doi.org/10.24215/18537863e080

Recepción: 02 Marzo 2020

Aprobación: 03 Abril 2020

Publicación: 01 Diciembre 2020

\begin{abstract}
Resumen: Este artículo propone una reflexión sobre las implicancias que las concepciones teórico-epistemológicas sobre la acción tienen a nivel del quehacer metodológico en el proceso de investigación. En particular, analiza las consecuencias metodológicas que tuvo la elección del pragmatismo como perspectiva teórica para construir y abordar un objeto de investigación particular: un conflicto por relocalizaciones en un barrio popular de la ciudad de La Plata entre 2013 y 2017. Se buscará dar cuenta de ciertos desplazamientos teóricoepistemológicos inspirados por esta corriente, que a la vez condujeron a modos específicos de desplegar el trabajo de campo etnográfico.
\end{abstract}

Palabras clave: Pragmatismo, Etnografía, Relocalizaciones, Conflicto habitacional.

\begin{abstract}
This article reflects on the implications that theoretical-epistemological conceptions of action have on the methodological level in the research process. In particular, it analyzes the methodological consequences of pragmatism as the theoretical perspective chosen to build and address a particular research object: a conflict over relocations in a popular neighborhood in the city of La Plata between 2013 and 2017. It will seek to account for certain theoretical-epistemological displacements inspired by this theoretical current, which at the same time led to specific ways of deploying ethnographic fieldwork.
\end{abstract}

Keywords: Pragmatism, Ethnography, Relocations, Conflict over habitat.

\section{INTRODUCCIÓN. ETNOGRAFÍA Y PRAgMATISMO: ALGUNOS DESPLAZAMIENTOS}

Este artículo reflexiona sobre la articulación entre teoría y metodología partiendo de la premisa de que nuestros supuestos teórico-epistemológicos tienen implicancias concretas en las decisiones metodológicas que tomamos. Para ello, el artículo se basa en una etnografía sobre un conflicto por relocalizaciones llevada adelante en La Plata en el período 2013-2017. En particular, explora algunas de las consecuencias que tuvo a nivel metodológico la elección del pragmatismo como perspectiva teórica para construir y abordar este objeto de investigación. 
El conflicto en cuestión se enmarcó en una situación estructural de largo alcance caracterizada por las dificultades de acceso de los sectores populares a la tierra y la vivienda en Argentina, a la vez que emergió a partir de un evento coyuntural que puso a la problemática del déficit habitacional en primer plano: una trágica inundación ocurrida en la ciudad de La Plata en abril del año 2013.

La ciudad de La Plata es la capital de la provincia de Buenos Aires. Las cuatro grandes avenidas que conforman la circunvalación y que marcan el límite entre el casco fundacional y los barrios del "Gran La Plata" simbolizan, en los sentidos locales de la ciudad, la frontera entre centro y periferia. En este heterogéneo "Gran La Plata" se ubican decenas de barrios populares. Con casi 130 villas y asentamientos para el año 2014, La Plata era de hecho la localidad con mayor cantidad de urbanizaciones informales de la provincia de Buenos Aires de acuerdo a un registro elaborado por el Ministerio de Infraestructura.

El 2 de abril de 2013 una imprevista y abundante lluvia inundó la ciudad en cuestión de horas. El agua, que en muchas zonas superó la altura de un metro por sobre el nivel del suelo, generó incontables destrozos materiales y se cobró la vida de 89 personas (reconocidas oficialmente). La inundación, que fue vivida y es recordada como una tragedia local, supuso momentáneamente la transgresión de esa frontera entre centro y periferia, ya que afectó a diversas zonas sin distinciones. Casi la totalidad del casco fundacional, tanto como los barrios populares de la periferia, se vieron atravesados por ella.

Si bien la causa inmediata de la inundación fue la abundancia y celeridad de las precipitaciones, interpretaciones posteriores pusieron el foco en la falta de controles en el desarrollo inmobiliario de los últimos años en la ciudad y centralmente en la ausencia de obras hidráulicas adecuadas y preventivas en los arroyos y canales de la zona. Esto conduciría al desarrollo de obras por parte del gobierno provincial, en la búsqueda por evitar futuras inundaciones, así como por responder a las demandas de diversos actores y especialmente de las asambleas de inundados que se constituyeron al calor de la tragedia.

Fue a partir de este evento entonces que el gobierno provincial comenzó a desarrollar en 2014 una obra hidráulica de gran envergadura que supuso, entre otras cosas, el ensanchamiento y hormigonado de un arroyo que atraviesa la periferia de la ciudad, y sobre cuyos márgenes se ubican decenas de asentamientos precarios. Este plan de obra se articulaba con un proyecto de relocalización de muchas de estas viviendas que "obstaculizaban" el ensanchamiento del arroyo.

La Chacra, ${ }^{1}$ un pequeño barrio conformado por población qom de la provincia de Chaco y familias provenientes de Paraguay, fue uno de los asentamientos localizados a la vera del arroyo que se vieron atravesados por esta obra. Allí surgiría un conflicto en torno al proyecto de relocalización, el cual dio origen a una red heterogénea (conformada por habitantes del barrio, militantes de una organización territorial, extensionistas universitarios, abogados) que no existía como actor organizado previamente y que en el devenir del conflicto se nuclearía en pos de la instalación de un reclamo ante los funcionarios públicos a cargo del proyecto de obra. ${ }^{2}$

El enfoque teórico-epistemológico para abordar este objeto de investigación fue elaborado en base a los aportes de la sociología pragmática francesa, especialmente del campo de estudios sobre acciones de denuncias y movilizaciones colectivas, a partir de las obras de Luc Boltanski y Daniel Cefaï. Problematizar este proceso desde los postulados teóricos de dicha corriente me condujo a maneras específicas de abordar etnográficamente el devenir del conflicto.

Nardacchione y Piovani (2017) inscriben al pragmatismo en lo que llaman "sociologías pos contemporáneas" en un doble sentido: cronológico, en tanto sus producciones son posteriores temporalmente a aquellas de la "teoría contemporánea" canónica, y sustancial, en la medida en que se proponen como una crítica de la obra del autor más referenciado de los contemporáneos: Pierre Bourdieu. Los autores sostienen que la recepción de estos debates en América Latina representa actualmente una "oportunidad", en la medida en que reconocen aquí "un cierto agotamiento de los modelos teóricos y epistemológicos (“contemporáneos")", sumado a una "inclinación relativamente consensual [de la sociología 
local] a tratar el problema de la pluralidad y la diversidad, disolviendo categorías totalizadoras de lo social" (Nardachione y Piovani, 2017, p. 6), como veremos que propone el pragmatismo.

Ahora bien, es posible afirmar que estas nuevas concepciones teóricas no supondrán necesariamente la elaboración de nuevas técnicas o abordajes metodológicos, sino más bien la renovación de sus modalidades de uso (Balerdi, Boix, Iuliano y Welschinger, 2017). Para el caso de la etnografía, Boix y Semán (2019) reflexionan sobre las consecuencias que tiene el pragmatismo como concepción renovada de la acción sobre el quehacer etnográfico, en tanto

el diario de campo en que sedimenta y leva el registro etnográfico se constituye en la escritura y la propia observación de maneras muy diferentes de acuerdo con la posición teórica del etnógrafo para construir y dimensionar sus objetos, para que ciertas cosas queden o no invisibilizadas a sus ojos, aun cuando ese observador esté dispuesto a que 'la realidad' lo desafíe y lo supere (Boix y Semán, 2019, p. 2).

Con esto no queremos sostener aquí que la etnografía sea método desprovisto de teoría o que el pragmatismo sea teoría desprovista de método. Por el contrario, la investigación sobre la que reflexiona este artículo se basó en la búsqueda por articular pragmatismo y etnografía como enfoques, entendiendo que es posible reconocer una afinidad entre ambos. En particular, coincidimos con algunos autores como Cefä (2013), Breviglieri y Stavo-Debauge (1999) y Baszanger y Dodier (2004) en reconocer la proximidad del pragmatismo con la etnografía por su mayor sensibilidad -en comparación con otros abordajes- para reconstruir lo que hacen los actores en situación (Balerdi et al., 2017, p. 8).

Desde este punto de vista, la etnografía se propone "seguir actos, actividades, acciones o interacciones, tal como se desarrollan en una situación dada" (Cefaï, 2013, p. 12), a partir de la observación prolongada de estas situaciones, teniendo como principal instrumento la "experiencia encarnada del investigador", procurando manejar con habilidad el acceso al terreno, la toma de notas lo más densa y precisa posible, y un análisis arraigado en esta experiencia de trabajo de campo (Cefaï, 2013).

A su vez, la etnografía es entendida aquí, siguiendo a Mariza Peirano (2014), precisamente como enfoque. Desde este punto de vista, no se trata del método que precede a la teoría, sino que posee en sí misma un carácter teórico, en la medida en la que nos permite confrontar la teoría con nuevos datos, y transformar así los puntos de vista teóricos preexistentes. Al decir de Cefaï, la etnografía construye teoría de una manera no dogmática, "en una dinámica que vincula las preguntas con los métodos que elegimos, los datos que recogemos y los problemas que resolvemos" (2013, p. 27).

Partiendo de esta concepción, la intención de este artículo es reponer las particularidades que asumió esta etnografía sobre un conflicto habitacional, en función de su articulación con las concepciones teóricoepistemológicas inspiradas en el pragmatismo que orientaron la investigación.

La opción por el pragmatismo me condujo a ciertos desplazamientos centrales tanto en torno a la concepción de los sujetos y de las acciones que investigaba, como del objeto mismo de la investigación. Estos desplazamientos implicaron fundamentalmente trasladar la mirada de los grupos preexistentes en el campo por separado, hacia las situaciones y prácticas que estaban operando en la conformación de un actor colectivo nuevo que los integraba en torno a un reclamo por relocalizaciones; y llevar la mirada de un barrio o un grupo social determinado hacia un conjunto de interacciones y situaciones determinadas. El objeto de la etnografía no fue el asentamiento, o sus habitantes, sino lo que -siguiendo a los actores- llamamos "el conflicto".

$\mathrm{El}$ argumento que quisiera sostener en este artículo es que estos desplazamientos teórico-epistemológicos tuvieron dos consecuencias metodológicas nodales: por un lado, si no existía un actor colectivo preconstituido y de lo que se trataba era de reconstruir las acciones que lo hacían emerger, entonces metodológicamente esto supuso no dialogar, entrevistar, o seguir únicamente a un conjunto pre-seleccionado de actores (una muestra pre-definida), sino ir incorporando a quienes se iban enlazando en esta acción colectiva en la medida en la que esta tomaba forma y se desarrollaba; y por otro lado, si el objeto de la investigación no era el barrio sino el conflicto, esto implicó que la etnografía se abocara a seguir este conflicto 
en los espacios sociales en los que se iba desplegando: así, el trabajo de campo inició circunscripto al barrio, pero pronto lo trascendió hacia otras escalas y espacios de interacción.

El artículo se inicia entonces con una presentación de las principales líneas teórico-epistemológicas del pragmatismo que inspiraron la investigación, para luego narrar el desarrollo y transformación del conflicto, y las decisiones metodológicas que fui tomando para abordarlo etnográficamente.

\section{Sujetos y ACCiONES COLECTIVAS EN EL PRAGMATISMo}

En el campo de estudios sobre politicidades y acciones colectivas, la sociología pragmática ha realizado aportes clave para la renovación de los modelos tradicionales de análisis. En contra de concepciones sustancialistas y naturalistas de los grupos sociales, los autores inscriptos en esta perspectiva han avanzado hacia la pregunta por cómo son hechos los colectivos. Así, más que centrar la atención en los movimientos sociales, aspirando a su estatus de sujetos colectivos, estos enfoques proponen desplazarla hacia las situaciones problemáticas (Cefaï, 2011) en las que estos se constituyen, hacia el trabajo social de definición y delimitación de los grupos (Boltanski, 2015), atendiendo a las acciones que les han dado forma y visibilidad.

Para Cefaï (2011), antes que probar con modelos preestablecidos que expliquen las motivaciones y orientaciones de la acción colectiva a priori, se debe describir y comprender "la situación problemática a la que las personas están confrontadas y qué las lleva en un momento dado a comprometerse en una acción colectiva" (Cefaï, 2011, p. 140). Esto permite a la investigación, y especialmente a la etnografía (Cefai\#, Carrel, Talpin, Eliasoph y Lichterman, 2012), acompañar los momentos de emergencia de una participación no programada o espontánea, dar cuenta de los procesos de adquisición de capacidades políticas, atender a los modos de participación que exceden a los canales de participación instituidos, e incluso comprender los sentidos del rechazo a participar.

A su vez, estos enfoques han contribuido al estudio de las acciones colectivas de reclamo, en términos de las capacidades para la instalación de denuncias en el espacio público -teniendo en cuenta las competencias de los actores para la crítica, lo que supone la elaboración de argumentos, el trabajo de generalización de la denuncia, la superación de pruebas (Boltanski, 2000)-.

Así, en contra de los modelos instrumentales o utilitaristas de análisis de la acción (que piensan la racionalidad en términos unidireccionales del cálculo costo/beneficio), la sociología pragmática "invoca una incertidumbre acerca de lo social que obliga a pensar la acción como una sucesión de pruebas sometidas a un ajuste permanente (ensayo-error)" (Nardacchione y Acevedo, 2013, p. 100). Esta indeterminación, que será uno de los aportes clave del enfoque pragmático a las teorías de la acción, conduce a la necesidad de volcar los análisis hacia lo que hacen los actores en situación. Una sociología de las prácticas situadas que nos conduce a: correr la atención de los actores colectivos como sujetos preconstituidos hacia los procesos intersticiales de asociación y formación de grupos; superar el análisis de los motivos de la acción política en términos de la deliberación racional y reponer en cambio los compromisos que conducen a los actores a participar en acciones colectivas; abandonar las concepciones estratégicas de la acción y en cambio reponer las exigencias de la gramática en la que esta se despliega (Cefaï, 2008).

Cefaï (2011) sostiene que el desplazamiento del análisis tradicional de las movilizaciones colectivas que propone la sociología pragmática tiene tres implicancias al nivel del hacer investigativo: partir de los contextos de experiencia de los propios actores en situación, no deificar macro-estructuras sino mostrar los procesos de coordinación e interacción que configuran macro-actores, y recurrir a métodos cualitativos de investigación. En particular, la investigación etnográfica permite seguir "las variaciones contextuales y las transformaciones temporales":

Más que considerar los colectivos como empresas mercantiles o comunidades étnicas, agrupaciones profesionales o partidos políticos, más que asignarles un principio único de existencia, basado en la clase o el género, la vecindad o el beneficio, y, en consecuencia, atribuir un tipo único de razones a los miembros, e identificar una lógica única respecto a sus intervenciones, 
hay que partir de una descripción compacta de sus experiencias de asociación y de reunión. Así, el sentido de estos modos de asociación aparece sólo gracias a una investigación etnográfica, que sigue las variaciones contextuales y las transformaciones temporales (Cefaï, 2011, p. 156).

En síntesis, este enfoque justifica y a su vez explica la relevancia de atender al proceso de conformación de las demandas o reclamos sin pretensiones efectistas (sin fijar el análisis al éxito o fracaso final de la acción colectiva) y sin asumir la existencia previa de un actor organizado. Antes que eso, atendiendo a cómo se trama una red de actores en el desarrollo mismo de la acción colectiva.

\section{Seguir EL CONFLiCto}

La investigación sobre la que se basa este artículo asumió el desafío de analizar y comprender el proceso de emergencia de un reclamo y de una red de actores que lo llevó adelante -proceso que fue concebido como conflictivo y nombrado como "conflicto" en términos nativos-. Consistió entonces en seguir etnográficamente el conflicto, atendiendo a las distintas escalas espaciales y temporales que fue atravesando en su devenir y a los modos de asociación que lo hicieron emerger.

Ello en parte fue posible gracias a que mi inserción en el campo estuvo dada por un doble rol: no sólo como etnógrafa sino también y paralelamente como miembro de uno de los actores de esta trama, un proyecto de extensión universitaria que desarrollaba actividades en el barrio desde hacía algunos años. ${ }^{3}$ Esto me permitió acceder al conflicto desde el momento mismo de su emergencia. Surgido en el barrio, sin embargo, este excedió pronto la escala barrial y, como sostuve anteriormente, comenzó a articular a nuevos actores y escenarios locales y provinciales.

A continuación describo el proceso de emergencia y transformación del conflicto. Esta reconstrucción buscará mostrar el despliegue de las acciones estudiadas, a la vez que ir reponiendo la estrategia metodológica que llamé seguir el conflicto.

La reconstrucción sigue un desarrollo cronológico, pero a la vez da cuenta de las dimensiones que emergen y distinguen a cada etapa del proceso. Estas dimensiones se condensan en categorías nativas como información, afectación, negociaciones, tiempos, que son construidas por los actores intervinientes y adquieren sentidos específicos en el desarrollo del conflicto, pero que asimismo se vuelven significativas para comprender este proceso analíticamente. ${ }^{4}$

\subsection{En busca de información}

Como sostuve al comienzo, el barrio de La Chacra es un pequeño asentamiento conformado por familias provenientes de Chaco y Paraguay que fueron migrando y asentándose en el lugar con escasos recursos materiales y a partir de la autoconstrucción de sus viviendas sobre los márgenes del arroyo. El conflicto se inicia en el barrio cuando la obra de canalización del arroyo comienza a vislumbrarse ya a poca distancia del mismo.

La normativa que estipulaba la realización de un ambicioso plan de infraestructura hidráulica en la región capital de la provincia, plan que incluía esta gran obra de ensanchamiento y hormigonado del arroyo y la relocalización de las viviendas ubicadas en sus márgenes, fue aprobado pasados apenas tres meses de la mayor inundación que experimentara la ciudad de La Plata. A poco más de un año de la aprobación de este proyecto, el escenario cotidiano de La Chacra comenzaba lentamente a transformarse: a dos o tres cuadras del barrio se observaban ya las grandes máquinas amarillas en el canal, cavando, cementando, avanzando.

Tanto la obra hidráulica como el proyecto de relocalización estaban a cargo del Ministerio de Infraestructura de la provincia. Sin embargo, por entonces los habitantes de La Chacra no habían recibido información oficial alguna por parte de los funcionarios al respecto de la obra y sus consecuencias para el 
barrio. Desde entonces, a partir de relatos parciales que comenzaron a circular por el barrio sobre una posible relocalización y sin que ninguna autoridad del Ministerio se acercara a informar a los vecinos, comenzó a tramarse un clima de temor e incertidumbre que marcó el escenario en el que inició el conflicto. Este clima de incertidumbre surgiría en base al desconocimiento que tenían no sólo los habitantes sino también otros actores con inserción en La Chacra -como éramos los miembros del proyecto de extensión- en torno a cuestiones relativas a la obra y a la relocalización que afectaría inminentemente al barrio. En charlas informales, a través de rumores y relatos de tercera mano, circulaba diferente información sobre aspectos técnicos de la obra y sus plazos. Y diferían las versiones acerca de la cantidad de metros en que se ensancharía el canal y acerca de la cantidad de metros de terreno que ese ensanchamiento afectaría de sus márgenes. La incertidumbre giraba también en torno a la relocalización, y eran estas incertezas las que más ansiedad o preocupación generaban: ¿qué viviendas deberían ser demolidas para el avance de la obra? ¿A dónde serían relocalizadas las familias que habitaban dichas viviendas? ¿Cuándo y bajo qué condiciones serían trasladadas?

Prontamente comenzaron a realizarse en el barrio asambleas que convocaron no sólo a sus habitantes sino también a los miembros del proyecto de extensión y a integrantes de una organización territorial con inserción en el territorio, el Movimiento Justicia y Libertad (MJL). Estos, a su vez, invitaron a participar también a un grupo de abogados nucleados en un colectivo de acción jurídica local. Esta red heterogénea de actores -que se congregaban por primera vez-comenzó a solicitar reuniones con funcionarios del Ministerio a los fines de conocer los "datos oficiales" de la obra, del proyecto de relocalización y de sus consecuencias para La Chacra.

De esta manera se fue desplegando un conjunto de acciones en torno a un reclamo particular: por información oficial y precisa. Y el criterio sobre el que se basó dicho reclamo fue el del acceso a la información oficial como derecho. El argumento de que el acceso a la información era un derecho de los habitantes del barrio que estaba siendo vulnerado por parte del Estado se convirtió en el criterio que justificó y orientó la acción en este primer tiempo del conflicto.

Estos acontecimientos me fueron conduciendo, en mi tarea de seguir el conflicto que comenzaba a configurarse, a integrarme a las asambleas barriales y a entrevistar a los habitantes de La Chacra, pero también a participar de los primeros encuentros con funcionarios en las oficinas del Ministerio y de reuniones que comenzamos a llevar a cabo con mis compañeros extensionistas, el dirigente del MJL y los miembros del colectivo de abogados en sus oficinas del centro de la ciudad. Comencé así en estos eventos a tomar las primeras notas de un diario de campo que, entre registros de observaciones, desgrabaciones de entrevistas y otros textos conformados por notas periodísticas, publicaciones en redes sociales y materiales escritos por los actores intervinientes, dataría su primera entrada en junio de 2013 y la última en diciembre de 2017.

\subsection{La relocalización como oportunidad}

De los encuentros con algunos funcionarios del Ministerio, los actores de la red construyeron el diagnóstico de que aquellos operaban sobre la base de información desigual y fragmentaria respecto a la obra. El desarrollo técnico estaba a cargo del área de hidráulica del Ministerio. Cuántos metros debía ocupar el canal en cada tramo de la obra y, por tanto, cuánto del margen del arroyo se vería afectado, eran datos que iban siendo construidos, como nos dijo un directivo del área de relocalizaciones, durante el avance mismo de la obra. Por lo tanto, la información precisa sobre cuántas y cuáles viviendas debían ser demolidas no parecía estar dada de antemano. Esto se evidenció en el hecho de que, tras aquellos encuentros, la información respecto a cuáles viviendas debían ser relocalizadas que los funcionarios comenzaron a brindar señalaba sólo a 6 u 8 hogares del barrio, cuando muchas más parecían ser las casas igualmente ubicadas sobre los márgenes del arroyo.

Este diagnóstico condujo a la red de actores que se iba tramando en torno al conflicto a percibir la importancia de realizar un relevamiento propio en La Chacra relativo a las condiciones habitacionales de los vecinos y su situación (cercanía y riesgo) respecto al arroyo. A partir de este relevamiento, el reclamo inicial 
por información oficial asumiría una nueva modalidad: se convertiría en un reclamo por ampliar el criterio de afectación que los funcionarios del Ministerio parecían sostener.

El relevamiento consistió en la aplicación de una encuesta a las 60 viviendas del barrio que se ubicaban al margen del arroyo (el cual, tras la obra de ensanchamiento y hormigonado, dejaría de ser un curso de agua repleto de vegetación y basura, y se convertiría en un gran canal de cemento de unos tres metros de profundidad). En base al análisis y clasificación de los resultados de este relevamiento, los miembros de la red concluyeron que los "afectados" por la obra no eran sólo las 6 u 8 viviendas que indicaban los funcionarios del Ministerio, sino unas 20 que, si no eran removidas, quedarían peligrosamente ubicadas al borde del canal. Esto condujo a la elaboración de un nuevo criterio de afectación que redefinió el reclamo y asimismo contribuyó a un cambio en la percepción del conflicto: la relocalización dejaría de ser percibida como una amenaza y se convertiría, para la mayoría de los vecinos, en una oportunidad. Oportunidad para dejar de vivir junto a un arroyo contaminado e inundable y de mejorar las condiciones habitacionales a partir de la obtención de viviendas, en sus palabras, "más lindas" y con títulos de propiedad.

En paralelo a la realización del relevamiento, el reclamo fue avanzando hacia otras instancias estatales: la Comisión Bicameral de Control y Fiscalización de la obra, la Defensoría del Pueblo y el Consejo Social de la Universidad Nacional de La Plata. Es en estas diversas instancias en que fue cobrando fuerza el argumento de que no eran sólo 6 u 8 las viviendas afectadas, como parecían sostener inicialmente los funcionarios de Infraestructura. Así, el relevamiento tuvo una gran influencia en el desarrollo del proceso, en tanto se convirtió en una base sólida y legítima para el reclamo, que fue utilizada como argumento en la denuncia ante estos diversos organismos. Se volvió en este sentido un insumo para la colectivización del reclamo, en la medida en la que fue utilizado como evidencia sólida y convincente en la retórica que fue desplegando la red para interpelar a estos nuevos actores.

Durante este proceso, fui buscando ampliar el registro etnográfico hacia estas nuevas instancias y actores que se iban enlazando en la medida en la que el conflicto, antes incipiente, iba ganando mayor envergadura e involucrando a nuevos actores institucionales. La descripción del proceso de elaboración del relevamiento y de análisis y utilización de sus datos que llevó adelante la red de actores fue también un insumo clave de este registro etnográfico.

\subsection{Negociaciones y criterios}

Luego de que el reclamo fue llevado a nuevos espacios institucionales que excedían al Ministerio de Infraestructura, sus funcionarios decidieron trasladar este asunto hacia un área del mismo que solía ocuparse de este tipo de conflictos: la Subsecretaría de Tierras. Los representantes de la Subsecretaría con quienes se comenzó a dialogar se presentaron dispuestos a aceptar el nuevo criterio de afectación propuesto por la red de actores del reclamo y a negociar las condiciones de una relocalización ampliada. De este modo, si el conflicto emergió de la mano de un reclamo por información oficial en el marco de un clima de incertidumbre, y se volcó luego hacia las disputas en torno al criterio de afectación, en este tercer tiempo se condensó en las negociaciones en torno a las condiciones de la relocalización para determinar cuántas y cuáles familias serían relocalizadas, a dónde y de qué manera.

La tarea etnográfica en este período, que abarcó unos vertiginosos tres meses de negociación, consistió en participar de cinco asambleas en el barrio, dos reuniones mantenidas en el marco del Consejo Social de la Universidad, varios encuentros con el dirigente del MJL y miembros del colectivo de abogados, y un recorrido junto a los vecinos por distintos barrios de la ciudad para evaluar destinos posibles de la relocalización. En todas estas instancias de discusión, disputa y establecimiento de acuerdos, se pusieron a jugar criterios, argumentos, miradas diversas respecto a las condiciones de la relocalización. En definitiva, busqué reponer etnográficamente la relocalización en tanto situación de participación política (Cefaï et at., 2012). 
Que la relocalización se hubiese transformado en algo deseable se expresó en el interés creciente de los vecinos de La Chacra por participar de las asambleas en el barrio y del recorrido por los posibles destinos de la relocalización, así como por formar parte de la "lista" de familias a relocalizar que se iría construyendo en este proceso. Sin embargo, si bien la relocalización comenzó a ser percibida progresivamente como una oportunidad para la mayoría, no fue bajo cualquier condición. Las viviendas, y sobre todo el nuevo barrio en el que estas se instalaran, debían ajustarse a determinados criterios de valoración que los vecinos pusieron a jugar durante las negociaciones: criterios vinculados a las condiciones habitacionales disponibles o posibles en los distintos lugares (cercanía o lejanía del centro, acceso a servicios públicos), a la estética y comodidad de las viviendas ofrecidas (tamaño, diseño, terminación), pero también a la "seguridad" con la que esperaban contar en el nuevo barrio. La puesta en juego de estos criterios condujo a que los vecinos rechazaran las opciones propuestas inicialmente por los funcionarios por no adecuarse a estas expectativas, y a que el conflicto continuara, en la búsqueda de nuevas opciones posibles de relocalización.

\subsection{Los tiempos y el desenlace}

Los criterios de valoración de los vecinos respecto a las viviendas y al barrio fueron marcando en parte el ritmo de las negociaciones. Estas, no obstante, también debieron atender a las dudas de los demás actores de la red que se debatían entre si aceptar o no las opciones ofrecidas por los funcionarios, temiendo que a la larga no surgieran otras alternativas viables. Este temor se fundaba en el hecho de que el predio que se eligiera para construir las nuevas viviendas no sólo debía cumplir con los criterios de valoración de los habitantes de La Chacra, sino que debía ser fiscal, ya que la provincia -según habían explicado los funcionarios de la Subsecretaría - no estaba en condiciones de comprar tierra privada.

Entre las opciones deseables y las opciones posibles, había un factor más que marcaba las negociaciones: el tiempo. La relocalización debía concretarse lo antes posible, dado que los funcionarios del Ministerio debían garantizar que la obra del arroyo, que formaba parte de la campaña del oficialismo provincial, culminara antes de los comicios electorales que tendrían lugar en octubre de 2015.

Finalmente, las elecciones dieron la victoria a la oposición a tres escalas: municipal, provincial y nacional. Estos resultados terminaron definiendo un final sospechado para la relocalización de La Chacra. Para cuando las elecciones y el cambio de gestión tuvieron lugar, hacía ya varias semanas que el ritmo del conflicto se había desacelerado drásticamente. Ya no estaban llevándose más a cabo las reuniones entre los actores de la red, las asambleas en el barrio, o los encuentros con los funcionarios. En cierto sentido, los actores del reclamo se habían dispuesto a esperar a que pasaran las elecciones, y esperaban un resultado favorable: esto es, uno que permitiera continuar con las negociaciones pasados los comicios. Pero este no se produjo y las condiciones habilitantes del reclamo cambiaron. De hecho, para fines de ese año el nuevo gobierno provincial presentó al Congreso una modificación a la Ley de Ministerios que suponía, entre otras cosas, el traslado de la mayoría de las áreas y responsabilidades que hasta entonces tenía la Subsecretaría de Tierras hacia el Ministerio de Desarrollo Social de la provincia. Este cambio fue recibido como una mala noticia por parte de los trabajadores de la Subsecretaría que, ante el "desguace" del organismo y alegando riesgos de continuidad en sus puestos laborales, organizaron diversas acciones de protesta (movilizaciones, asambleas, cese de tareas) durante varios meses. La noticia también fue rechazada públicamente por organizaciones sociales con militancia en materia de hábitat y por el Consejo Social de la Universidad, que para diciembre publicó en las redes sociales un comunicado alertando sobre el "desmembramiento de la política de vivienda".

Las elecciones significaron una bisagra en el conflicto. El cambio de gestión, y con ella la desaparición de los interlocutores con los que la red llevaba adelante las negociaciones, se tradujo rápidamente en la pérdida de las condiciones que hasta entonces habían habilitado el reclamo y la posibilidad misma de obtener una solución por parte del gobierno provincial. Esto será leído posteriormente por los actores de la red como la confirmación de que la preocupación por los tiempos electorales era clave, y que la expectativa de que el 
oficialismo ganara las elecciones como garantía de resolución futura del conflicto fue un "error de cálculo" que tuvo sus costos.

Como sostienen Cefaï et al. (2012), seguir el proceso mismo de emergencia y transformación de una acción colectiva o una demanda permite atender a reclamos que no logran los resultados esperados en su formulación, que quedan inconclusos, o que adquieren otros rumbos distintos a los esperados cuando se formulan. Mi trabajo de campo no se detuvo luego de las elecciones, sino que continuó algún tiempo más, relevando algunos de los dilemas que continuaron permeando las vidas de los habitantes de La Chacra en torno al arroyo y a la obra luego de desactivado el reclamo. De esta manera, el conflicto como categoría nativa, pero también como objeto de investigación, incluyó la desactivación del reclamo y la posterior manifestación de sus tensiones irresueltas.

Con esta intención, en camino de cerrar el trabajo de campo decidí realizar una serie de entrevistas a algunos actores en particular. Estas se sumarían a las tantas conversaciones mantenidas con ellos durante diversas situaciones de interacción a lo largo del desarrollo del conflicto, pero fueron realizadas en contextos espacio-temporales diferentes a aquellas charlas informales al calor de los eventos. Esto permitió habilitar una reflexión retrospectiva sobre la dinámica del conflicto, y poner en juego lecturas posteriores sobre el devenir de los acontecimientos, en cierto modo despegadas de aquellos marcos de interacción habituales. Esta decisión estuvo orientada por la intención de reconstruir las interpretaciones y elaboraciones críticas que produjeron mis interlocutores sobre el conflicto, en línea con la apuesta pragmática de atender a las propias competencias, saberes, teorías que desarrollan los actores.

\section{CONSIDERACIONES FINALES}

El enfoque teórico-metodológico propuesto de seguir el conflicto, elaborado a partir de un cruce entre etnografía (Cefa, 2013; Peirano, 2014) y determinadas premisas de la sociología pragmática (Boltanski, 2000, 2011, 2015; Cefa, 2009, 2011), condujo a la investigación a seguir en el proceso de desarrollo del conflicto a actores, escenarios y temporalidades que iban excediendo la escala barrial y el ahora. Seguir el conflicto permitió reponer las prácticas que, en su propio devenir, producían escalas espaciales y temporales que iban más allá del presente barrial.

Como sostuvieron mis interlocutores en este proceso, el conflicto atravesó tres escalas, en la medida en que se trató de una problemática barrial -la relocalización de algunas de las viviendas de La Chacra-, inscripta en una problemática local -la inundación y sus consecuencias para la ciudad de La Plata-, lo que a su vez puso en primer plano una problemática provincial -el problema del acceso y gestión de la tierra en la provincia y las precarias condiciones habitacionales de las miles de personas asentadas en los márgenes de los arroyos de la zona-.

Estas problemáticas, asimismo, expresaban tiempos distintos para los actores que irían orientando el desarrollo del conflicto: los tiempos de la obra hidráulica y la presión por su concreción, de la construcción de las viviendas, de los distintos actores involucrados que ponían a jugar sus necesidades y criterios, y los del contexto electoral.

En este escenario tramado a múltiples escalas y temporalidades, seguir el conflicto se constituyó en la tarea que llevé adelante en el doble rol de extensionista e investigadora. El objetivo fue el de reconstruir las acciones, estrategias, mecanismos a partir de los cuales una red de actores, que no existía como tal previamente, construyó e instaló un reclamo por hábitat.

Como sostuve al comienzo, es posible afirmar que no existe entre los autores que podríamos inscribir en la corriente pragmática o pragmatista una renovación de los abordajes metodológicos o técnicos, sino más bien de las modalidades de uso de dichas técnicas (Balerdi et al., 2017). La opción por el pragmatismo como marco teórico-epistemológico desde el cual abordar este objeto de investigación me condujo a desplegar una modalidad de uso específica de la etnografía, antes que a proponer un abordaje metodológico 
nuevo. Partiendo de una concepción de la etnografía como enfoque (Peirano, 2014), intenté desplegar una modadalidad de uso del mismo ajustada a la singularidad del objeto de estudio. Se trató de un uso orientado por una serie de desplazamientos en las concepciones de la acción que investigaba: seguir etnográficamente las formas de asociación emergentes, la construcción de una red de actores heterogénea y contingente, la transformación de una demanda que fue modificando su contenido y sus interlocutores, el devenir de un conflicto que se inició en un espacio social determinado y lo trascendió.

\section{REFERENCIAS}

Aliano, N.; Balerdi, S.; Hang, J.; Herrera, N. (2018). Reflexividad y roles en el trabajo de campo etnográfico. En Piovani, J. I. y Muñiz Terra, L. (Comp.), ¿Condenados a la reflexividad? Apuntes para repensar el proceso de investigación social (p. 289). Buenos Aires: CLACSO - Editorial Biblos.

Balerdi, S., Boix, O., Iuliano, R. y Welschinger, N. (2017). Sociologías pragmatistas: Continuidades entre postulados teóricos y operaciones metodológicas. Cuestiones de Sociología, 16. DOI: https://doi.org/10.24215/23468904 e027

Baszanger, I. y Dodier, N. (2004). Ethnography: relating the part to the whole. En D. Silverman (Ed.), Qualitative research: theory, method and practice (pp. 9-34). London: SAGE Publications.

Boix, O., y Semán, P. (2019). Etnografía, mediaciones y pragmatismo. Revista Latinoamericana De Metodología De Las Ciencias Sociales (Relmecs), 9(1), 1-12. DOI: https://doi.org/10.24215/18537863e048.

Boltanski, L. (2000). El Amor y la Justicia como competencias: Tres ensayos de sociología de la acción. Buenos Aires: Amorrortu.

Boltanski, L. (2011). On critique: A sociology of emancipation. Cambridge: Polity Press.

Boltanski, L. (2015). Cómo se objetivó un grupo social: Los 'cuadros' en Francia, 1936-1945. Instersticios: Revista sociológica de Pensamiento Crítico, 9(2), 75-87.

Breviglieri, M. y Stavo-Debauge, J. (1999). Le geste pragmatique de la sociologie française. Autour des travaux de Luc Boltanski et Laurent Thévenot. Antropolitica, 7, 7-22.

Cefaï, D. (2008). Los marcos de la acción colectiva. En A. Natalucci (Ed.), Sujetos, movimientos y memorias. Sobre los relatos del pasado y los modos de confrontación contemporáneos (p. 230). La Plata: Ediciones Al Margen.

Cefaï, D. (2009). ¿Cómo nos movilizamos? El aporte de un enfoque pragmático a la sociología de la acción colectiva" [Versión castellana de: "Comment se mobilise-t- on? L'apport d'une approche pragmatiste á la sociologie de l'action collective"]. Sociologie et sociétés, 41/2, 245-269.

Cefaï, D. (2011). Diez propuestas para el estudio de las movilizaciones colectivas: De la experiencia al compromiso. Revista de Sociología, 26, 137-166.

Cefaï, D. (2013). ¿Qué es la etnografía? Debates contemporáneos. Arraigamientos, operaciones y experiencias del trabajo de campo. Persona y sociedad, 27(1), 101-119.

Cefai\#, D., Carrel, M., Talpin, J., Eliasoph, N. \& Lichterman, P. (2012). Ethnographies de la participation. Participations, 4(3), 7-48.

Nardacchione, G. y Acevedo, M. H. (2013). Las sociologías pragmático- pragmatistas puestas a prueba en Ame\#rica Latina. Revista Argentina de Sociología, 9-10(17-18), 87-118.

Nardacchione, G., y Piovani, J. I. (2017). Las sociologías post contemporáneas: discusiones teóricas, estrategias metodológicas y prácticas de investigación en contextos diferentes. Cuestiones De Sociología, 16, 1-10. DOI: ht tps://doi.org/10.24215/23468904e023

Peirano, M. (2014). Etnografia não é método. Horizontes Antropológicos, 20(42), 377-391. DOI: http://dx.doi.org/1 $0.1590 /$ S0104-71832014000200015 


\section{Notas}

1 Los nombres de lugares y personas han sido modificados para resguardar el anonimato.

2 Para un desarrollo más exhaustivo de este proceso ver Balerdi, Boix, Iuliano y Welschinger (2017).

3 Para un análisis sobre las implicancias a nivel de la reflexividad metodológica de esta doble inserción ver Aliano, Balerdi, Hang y Herrera (2018).

4 Es importante aclarar que esta estrategia de exposición otorgará al proceso estudiado un efecto de linealidad algo artificial, como si el conflicto tuviera un principio, un desarrollo y un final. Reponer las categorías analíticas que caracterizan cada etapa del proceso busca tensionar justamente este efecto, al poner en evidencia que se trata de una reconstrucción analítica, interpretando, hilando y analizando el devenir de situaciones, acciones y actores que en el curso de su desarrollo son en gran medida indeterminadas. 